\title{
Correction to: Removal of an Acute Subdural Hematoma Associated with High-Energy Trauma: Auxiliary Use of Emergency Trepanning and Endoscopy
}

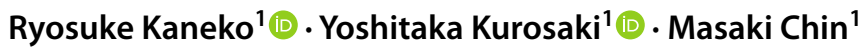

Published online: 13 July 2021

(c) Association of Surgeons of India 2021

\section{Correction to: Indian Journal of Surgery}

https://doi.org/10.1007/s12262-021-03003-w

The article "Removal of an Acute Subdural Hematoma Associated with High-Energy Trauma: Auxiliary Use of Emergency Trepanning and Endoscopy", written by Ryosuke Kaneko, Yoshitaka Kurosaki, and Masaki Chin, was originally published online on the publisher's internet portal on June 21, 2021 with Open Access under a Creative Commons Attribution (CC BY) license 4.0.

With the authors' decision to cancel Open Access the copyright of the article changed on July 6, 2021 to ()
Association of Surgeons of India 2021 with all rights reserved.

The original article has been corrected.

Publisher's Note Springer Nature remains neutral with regard to jurisdictional claims in published maps and institutional affiliations.

The original article can be found online at https://doi.org/10.1007/ s12262-021-03003-w.

Yoshitaka Kurosaki

kurosaki0106@gmail.com

1 Department of Neurosurgery, Kurashiki Central Hospital,

1-1-1 Miwa, Kurashiki, Japan 